\title{
Resistência e reciprocidade: comportamento in situ de pertencimento na feira do produtor em Morretes - PR ${ }^{1}$
}

\section{Resistance and reciprocity: the in-situ behavior of belonging At the producers fair in Morretes - PR}

\author{
Pamela Natali Ferreira de Jesus ${ }^{*}$ \\ Valdir Frigo Denardin ${ }^{* *}$ \\ Mayra Tayza Sulzbach ${ }^{\star \star \star}$
}

\begin{abstract}
Resumo: O presente trabalho teve como objetivo apresentar os resultados de uma pesquisa que buscava averiguar a existência de uma economia contra hegemônica num espaço de troca monetária, no caso na Feira do Produtor em Morretes no Litoral do Paraná. Utilizou-se a metodologia de pesquisa teórica indutiva, observação etnográfica, descritiva e analítica do objeto de estudo. Os resultados mostram que na Feira do Produtor há relações sociais de reciprocidade que se sobrepõe as relações de ganhos financeiros individuais. A Feira do Produtor na prática pode ser observada como um sítio de pertencimento local, um local de resistência contra a racionalidade globalizante, por nela ocorrer a valorização da cultura local, onde as pessoas se identificam ao mesmo tempo em que a atividade econômica ocorre. Concluiu-se que, no espaço Feira, o homo situs destaca-se nas relações sociais, organizando o sítio com base em relações de reciprocidade.
\end{abstract}

Palavras-chave:DesenvolvimentoTerritorial.Reciprocidade.Sustentabilidade.

Abstract: The present work had as objective to present the results of a research that sought to ascertain the existence of a counter-hegemonic

\footnotetext{
${ }^{1}$ Uma versão preliminar deste texto foi apresentada no "II SEMINÁRIO INTERNACIONAL DE PÓS-GRADUAÇÃO EM DESENVOLVIMENTO RURAL SUSTENTÁVEL” em Foz do Iguaçu, entre 07 a 09 de agosto de 2019, sendo indicado pelo evento para compor este volume especial.

* Mestranda em Desenvolvimento Territorial Sustentável pela Universidade Federal do Paraná (UFPR); Especialista em Educação Ambiental e Sustentabilidade pelo Centro Universitário Internacional (UNINTER); Graduada em Ciências Biológicas pela Universidade Estadual do Paraná (UNESPAR); E-mail: pamynatalie@gmail.com.

${ }^{* *}$ Pós-doutor em Economia Regional pela Laboratoire Dynamiques Sociales et Recomposition des Espaces (LADYSS, França); Doutor em Ciências Sociais e Desenvolvimento, Agricultura e Sociedade pela Universidade Federal Rural do Rio de Janeiro (UFRRJ); Mestre em Economia Rural pela Universidade Federal do Rio Grande do Sul (UFRGS); Graduado em Ciências Econômicas pela Universidade Federal de Santa Maria (UFSM); Professor da Universidade Federal do Paraná (UFPR). E-mail: valdirfd@ufpr.br.

*** Doutorado em Desenvolvimento Econômico pela Universidade Federal de Santa Maria. Professora Associado da UFPR. Docente dos Programas de Pós-Graduação em Desenvolvimento Territorial Sustentável e Meio Ambiente e Desenvolvimento da UFPR. E-mail: mayrasulzbach@yahoo.com.br
} 
economy in a space of monetary exchange, in the case of the Producer's Fair in Morretes on the coast of Paraná. The methodology of theoretical inductive research, ethnographic, descriptive and analytical observation of the object of study was used. The results show that in the Producer Fair there are social relations of reciprocity that overlap the relations of individual financial gains. The Producer Fair in practice can be seen as a place of local belonging, a place of resistance against globalizing rationality, because it takes place the valorization of local culture, where people identify themselves at the same time as economic activity occurs. It was concluded that, in the Feira space, homo situs stands out in social relations, it organizes the site based on reciprocity relations.

Keywords: Territorial Development. Reciprocity. Sustainability.

Recebido em 14/11/2019. Aceito em 11/03/2020.

\section{Introdução}

A economia de mercado dita "natural", que levou o homem à lógica destrutiva da natureza também o desvinculou de sua gênese: ser humano (POLANYI, 2012). O natural constitui o locus onde o ser humano tem seu habitat, sendo a espécie humana produto dela própria, ou seja, da natureza. A economia de mercado tornou as relações de trabalho e renda superiores às das humanas, contribuindo para a dissolução da natureza e do Homem. O Homem, na lógica do mercado autorregulável, se reduz a uma mercadoria - um indivíduo que decide a partir de uma só racionalidade, a dita econômica - Homo oeconomicus de Zaoual (2003). Contrapondo a esse modelo de organização produtiva e de distribuição, provedor desse tipo de Homem, que formam as sociedades capitalistas, os das sociedades tribais, estudadas no mesmo século por Mauss (2003), estavam baseados em outras racionalidades, destacando-se o da dádiva e/ou da reciprocidade, coexistindo com as trocas monetárias (POLANYI, 2012). Tal como Polanyi (2012), Zaoual (2003) alerta sobre a existência de outras racionalidades que coexistem nas sociedades capitalistas; racionalidades que podem estar estruturadas nas relações sociais, as quais ele denominou de racionalidades situadas, definindo os homens que atuam com tal racionalidade de Homo situs (ZAOUAL, 2003). São espaços ou locais nos quais a organização social e produtiva é estabelecida por um tipo de homem situado, o qual estabelece sítios simbólicos de pertencimento a partir de outrem ou da natureza, promovendo dinâmicas materiais e imateriais relacionadas que dão sentido a sua vida. A localização e compreensão na prática outras formas de organização da sociedade, mesmo que seja no campo da pesquisa, devem apoiar-se na promoção de outra sociedade, mais humana, com menos desigualdades e ambientalmente sustentável.

A Feira do Produtor do município de Morretes, Litoral do estado do Paraná, possui elementos que apresentam indícios de ser um sítio simbólico de pertencimento, por ser um espaço público de uso recorrente, onde seus frequentadores estabelecem complexas relações sociais e de troca: um espaço de fonte de renda de famílias rurais ou não, que vendem o produto do 
seu trabalho para compradores, em geral urbanos, os quais desfrutam do espaço para além dos produtos adquiridos.

A Feira do Produtor de Morretes, pela sua recorrência talvez possa ser um sítio de pertencimento local, influenciado por diferentes motivações, estabelecendo diferentes racionalidades que se expressam no comportamento dos atores sociais. Neste sentido, o presente trabalho busca, através da observação etnográfica do comportamento dos vendedores e compradores, constatar a existência ou não de um Homo situs no espaço da Feira do Produtor de Morretes, o qual teve sua origem fundamentada para as trocas monetárias, ou seja, num espaço no qual a racionalidade de um Homo oeconomicus deveria prevalecer.

\section{Método}

Trata-se de uma pesquisa social, fundamentada numa revisão teórica, baseada em Mauss (2003), Polanyi (2012) e Zaoual (2003), que conduz à compreensão de princípios, os quais guiam o comportamento dos homens, movendo diferentes racionalidades, entre as quais estão às acionadas nas trocas mercantis e também nas das trocas não monetárias, auxiliando na compreensão de outras economias, e em Saborin (2011), que orientou para a eleição da variável "reciprocidade", e sua proposta de interpretação, como um tipo de princípio que poderia estar presente nas trocas de produtos rurais em espaços urbanos de sociedades capitalistas.

Com base nesses referenciais emergiu o local da pesquisa: o espaço de comercialização (troca) de produtos da área rural em área urbana, preferencialmente vendidos pelo produtor ou pela agricultura familiar; espaço que, por pressuposto, os atores exerceriam outras racionalidades. A observação etnográfica, realizada em junho de 2018, ocorreu na Feira do Produtor de Morretes - Paraná.

A partir da observação e diálogos do pesquisador com os feirantes, optou-se pela metodologia descritiva. A pesquisa etnográfica ocorreu, conforme Hammersley (1990), em cinco etapas: 1) observação do comportamento das pessoas no seu contexto habitual, sendo utilizado o caderno de campo; 2) levantamento das informações por meio de conversação informal nos dias da ocorrência da feira do produtor, desde a abertura ao fechamento; 3 ) o movimento do grupo restrito de pessoas que participava da Feira foi, nos diversos momentos, desenhados em papel a fim de possibilitar a compreensão; 4) a categoria teórica "reciprocidade" binária e ternária simétrica foram utilizadas para validar a existência de um sítio de pertencimento pelos sujeitos que frequentam a Feira e a Feira ser interpretada como um sítio simbólico de pertencimento, um lugar de resistência; e 5) a análise das informações foram interpretadas a luz do significado teórico da categoria de análise, assumindo a forma descritiva. A pesquisa não buscou quantificar para analisar por métodos estatísticos o objeto de pesquisa. Desta maneira, essa pesquisa decorreu em grande medida da capacidade interpretativa do pesquisador, possibilitando um contato estreito e longo com a realidade proposta neste estudo.

\section{Discussão teórica}

Polanyi (2012) ressalta que, a troca monetária nas diferentes sociedades sempre teve seu espaço, mas foi somente na Idade Contemporânea que o mercado torna a moeda autônoma e dominante. Como resultado da produção em busca do dinheiro, o homem chegou à lógica destrutiva da própria natureza humana, transformando tudo em mercadoria, alterando inclusive 
as relações entre os homens nas sociedades e desses com o ecossistema. Com a maximização da produção ampliaram-se as desigualdades sociais e os prejuízos ambientais, esses sem precedentes.

Polanyi (2012) aponta que, a transformação da terra e do trabalho em mercadoria, que promoveu o sistema capitalista ou a economia de mercado, acarretou no desmoronamento social. Defende ainda que, a ilusão da mercadoria sujeitou a natureza e o homem às "leis do mercado", e que a sociedade regulada pelo mercado se sustentaria. Nessa, o homem busca sua própria destruição, já que na busca de maximização das utilidades na produção, o homem corrompe suas liberdades, levando-o a pensar que não há outra economia ou outra forma de subsistência, isto é, outro modo de viver. Para Polanyi (2012), o modelo autorregulável, cuja quantidade e os preços independem da reprodução dos fatores de produção, é uma falácia; um modo desenraizado de sociedade, que separa o homem da sua própria natureza, a natureza (LESSA, 2011). Salienta-se que, o homem ao ser e fazer parte da natureza deve respeitá-la, conduzindo a sociedade ao desenvolvimento humano (SEN, 2010) e não econômico.

Para Zaoual (2003), a globalização desse modelo de desenvolvimento fez com que o ser humano fosse reduzido à condição de produção e consumo, comprimindo outras dimensões de sua vida - cultural, social e ecológica; reduzido à noção de utilidade e satisfação relativa de necessidades, sugerindo assim que a racionalidade econômica é uma falácia. Furtado (1974) denominou esse modelo de desenvolvimento de mito. O autor argumenta que a busca incessante pelo crescimento e lucro máximo se contrapõe à acepção de outra economia, a qual só é possível por meio de uma relação ética entre a economia e a política.

Outras economias, tal como as baseadas na reciprocidade e da redistribuição, fundamentadas em princípios enraizados, os quais foram relatadas na obra de Polanyi (2012) e observadas por Mauss (2003). Mauss (2003) ao comparar as iniciativas de circulação de bens das sociedades primitivas, tanto da Polinésia, Melanésia e do Noroeste americano, identificou que as relações sociais se davam por trocas anti-utilitaristas, não estando relacionadas à economia dita natural ${ }^{2}$. As trocas implicavam em fatos sociais: o ato da troca não estava desvinculado da economia, da política, da religião, da estética ou do parentesco. O autor evidencia que, essas sociedades não eram compostas por indivíduos que trocavam mercadorias, eram coletividades que estabeleciam trocas como dádivas. A dádiva era a troca de bens materiais ou imateriais que estabelecia vínculos subjetivos entre os que a realizavam. A oferta estava relacionada à disponibilidade de algo de si para o outro.

Conforme Mauss (2003), as instituições das sociedades tribais possuíam um regime social para o ato de trocar que não era motivado exclusivamente pela troca de "bens e riquezas, bens móveis e imóveis" (MAUSS, 2003, p. 203). As "amabilidades, banquetes, ritos, serviços militares, mulheres, crianças, danças, festas” trocados constituíam 'matéria espiritual' (MAUSS, 2003, p. 203). A dádiva não era um mero sistema de "intercâmbio" (MAUSS, 2003, p. 240). O intercâmbio era uma relação de interesse com reciprocidade mínima, ou seja, no intercâmbio procurava-se satisfazer o interesse próprio.

A dádiva, descrita por Mauss (2003), é uma troca que une; é uma troca que origina valor simbólico de finalidade moral e produz sentimento de aliança entre os envolvidos. 0 autor destaca que a dádiva se fundamenta em três princípios inseparáveis: dar, receber e retribuir. Sendo assim descritos: o ato de dar, como disponibilidade à iniciativa e assumir o risco de rejeição; o ato de receber, como disponibilidade à iniciativa alheia e; o ato de retribuir, como disponibilidade de unificar e tornar-se um com o outro.

\footnotetext{
${ }^{2}$ Natural é a naturalização da economia de mercado como sendo a única, aceita e sem questionamento.
} 
Para Mauss (2003), os contratos nessas sociedades eram firmados mediante a troca, sendo essa uma simples mobilização dos recursos, um meio, importava o contrato social firmado. 0 autor descreve que: as almas misturam-se nas coisas e as coisas nas almas, "misturam-se as vidas, e assim as pessoas e as coisas misturadas saem cada qual de sua esfera e se misturam" (MAUSS, 2003, p. 212). As trocas naquelas sociedades remetiam a um sentimento mútuo, nelas a honra, o prestígio, o desprendimento e a solidariedade não eram palavras vãs. O autor (MAUSS, 2003, p. 195) relata que, em algumas tribos a noção de valor não utilitário tinha poder mágico ligado a ritos, ao mana e ao hau e a uma "obrigação absoluta de retribuir as dádivas sob pena de perder esse mana".

Numa passagem da obra de Polanyi (2012, p. 61), o autor argumenta que "nas condições tribais a solidariedade era protegida pelos costumes e tradições, a vida econômica estava inserida na organização social, não havia lugar para transações econômicas"; que "a justiça e o direito se encarnavam em instituições mais antigas" e; que a "sociedade não era organizada de maneira mercantil, o preço, bens e riquezas não eram considerados justos somente quando vinham do mercado" (lucro e interesse) (POLANYI, 2012, p. 60).

Conforme Polanyi (2012, p. 55), há muito a aprender com essas sociedades, enfatizando que "a sociedade do século XIX organizou-se de um modo que fazia com que apenas a fome e o lucro fossem motivações eficazes para o indivíduo participar da vida econômica".

Para Polanyi (2012, p. 60) "os seres humanos trabalham por muitas razões desde que vivam em um grupo social definido":

O kula dos nativos das Ilhas Trobriand, um dos maiores intricados sistemas de trocas [...], é sobretudo uma busca estética [...], assim, os monges, os habitantes da Melanésia ocidental, os vassalos [...] eram conduzidos pela religião, a estética, os costumes, a honra [...] (POLANYI, 2012, p. 60).

Num tempo não tão longe e numa sociedade em que a acumulação do capital ainda busca sua hegemonia, limitado pelos contra movimentos, Sabourin (2011) analisando o meio rural argumenta que, coexistem reciprocidades mediadas por regras de âmbito local. Durante a venda direta entre produtor e comprador, esses são capazes de manter vínculos afetivos e éticos, os quais são denominados pelo autor de reciprocidade binária. Já, quando a venda ocorre por uma segunda pessoa que não o produtor, um corretor, esse cria prestígio pela mediação das informações do produto e do produtor, sendo denominando pelo autor de reciprocidade ternária.

Para Sabourin (2011), a reciprocidade estabelecida em dar com o compromisso de receber gera valores e sentimentos diferenciados, assim propõem quatro diferentes reciprocidades, conforme suas observações. A reciprocidade assimétrica, que é aquela que não se limita a relação de dádiva/contra dádiva entre os pares ou os grupos sociais, proporcionando reciprocidades positivas ou negativas; a reciprocidade simétrica, gerada por valores afetivos ou éticos; a reciprocidade bilateral simétrica, gerada por sentimentos de amizade ou justiça e; a reciprocidade ternária, criada a partir da responsabilidade em relação ao bem comum, ao meio ambiente ou às futuras gerações. Como toda relação envolve no mínimo duas pessoas, Sabourin (2011) as subdividiu em: unilateral, que ocorre a partir de um, sendo o outro receptor, tais como aquelas que ocorrem na transmissão de saberes ou na transferência do patrimônio dos mais velhos para os mais novos, e bilateral, que ocorre a partir do doador e do receptor, não sendo possível transferir para um terceiro. A reciprocidade para o autor ocorre em três níveis: no real, onde a totalidade é o impensável confrontando-se com os limites do ser humano no estado de consciência e subconsciência; 
no simbólico, inferido a partir das relações do sujeito com seu espaço, em um sistema de valores impostos pela lei da oferta e demanda (linguagem); e no imaginário, elencado pelo prestígio ou vingança para dar lugar a formas de reciprocidade positivas ou negativas (representações).

Para Sabourin (2011), o contrato social ou a democracia política colocou a reciprocidade em segundo plano, visto que não foi capaz de lidar com a produção de excedentes em estruturas simétricas ou em economias mais humanas. Para o autor, a sociedade foi reduzida a um sistema de troca de maximizações individualistas, contudo, suas análises do rural o permitiram argumentar que, as atividades econômicas podem ser motivadas pela "satisfação da necessidade do outro e manutenção de laços sociais” (SABOURIN, 2011, p. 34), gerando valores afetivos, imateriais, éticos, ajuda mútua e manejo compartilhado.

Para Polanyi (2012), a reversão do desenraizamento da economia de mercado ou da economia ser apenas uma das dimensões da vida passa pela instituição política, a qual deve ser controlada pela sociedade, permitindo liberdades, e para tal: o trabalho, a terra e o dinheiro não podem ser tratados como mercadorias.

Trazendo para o debate a regulação da sociedade pelos seus atores, Zaoual (2003) propõe o conceito de Homo situs, caracterizando-o como um homem que interage no território onde vive; um homem que busca estar em conformidade com o seu meio social (regras do local de Sabourin, 2011) e ecológico, estabelecendo sítios simbólicos de pertencimento, ou reciprocidades simétricas bilaterais ou ternárias, como proposto por Sabourin (2011).

Mauss (2003, p. 301) apresenta a reciprocidade como uma alternativa a ser adotada, um princípio de vida: "sair de si, dar, de maneira livre e obrigatória”. Polanyi (2012), na mesma linha apresenta que a reciprocidade, a redistribuição e a troca são princípios diferentes que movem sociedades, assim não existe apenas uma economia, existem diferentes economias e sociedades. Para completar, Sabourin (2011) aponta a existência de diferentes reciprocidades em meio às relações de trocas monetárias, dado que os atores assumem responsabilidades para um comum, tal como na reciprocidade ternária, movida por um sentimento de mudança. Portanto, subsistem diferentes reciprocidades que movem trocas monetárias.

Um mundo de desigualdades se apresenta como um mosaico, no sentido figurativo por Zaoual (2003). Nesse mundo, de acordo com o autor, a economia necessita ser solidária, por reunir confiabilidade, autonomia e cooperação, dimensões fundamentais para criar diferentes sítios simbólicos de pertencimento. Um homem concreto, situado, é aquele que cria um sítio simbólico de pertencimento, que cria um local de ancoragem, de confiabilidade, sobre o qual o homem composto de entidades imateriais estabelece: sua caixa preta, originária de crenças, experiência, memória e trajetória, sua caixa conceitual, originária de saber social, teorias e modelos, e sua caixa de ferramentas, originária de ofícios e modelos de ação. É com essas caixas que o Homo situs se insere e pratica atitudes que envolvem diversidade e respeito com o outro e com o meio ambiente. 0 Homo situs é o homem sujeito de sua própria história, é o ator. $O$ autor ressalta que o conhecimento processado pelo homem não separa o social, as crenças e os valores, portanto, a racionalidade é uma construção social capaz de transforma-se e de transformar os rumos da humanidade.

\section{Espaço de interação humana: a Feira do Produtor de Morretes}

A Feira do Produtor, objeto de observação dos sujeitos da pesquisa, localizada na Praça Rocha Pombo - centro urbano do município de Morretes, Litoral do Paraná, foi criada com o apoio do Instituto de Assistência Técnica e Extensão Rural do Paraná (EMATER/PR) e da Secretaria de 
Agricultura e Produtores Rurais/Prefeitura Municipal, com a participação ativa dos produtores (MORRETES, 2018). Na Feira, que desde 2010 ocorre todas as sextas-feiras das $18 \mathrm{~h}$ às $22 \mathrm{~h}: 30 \mathrm{~min}$, se observa a venda de produtos alimentícios de consumo local, tais como tapioca, espetinhos e bererecas e de alimentos de consumo fora do local, como compotas e vegetais. A Feira dispõe de equipamentos para atender aproximadamente 120 pessoas sentadas (FIGURA 1).

Figura 1 - Feira do Produtor em Morretes - Paraná

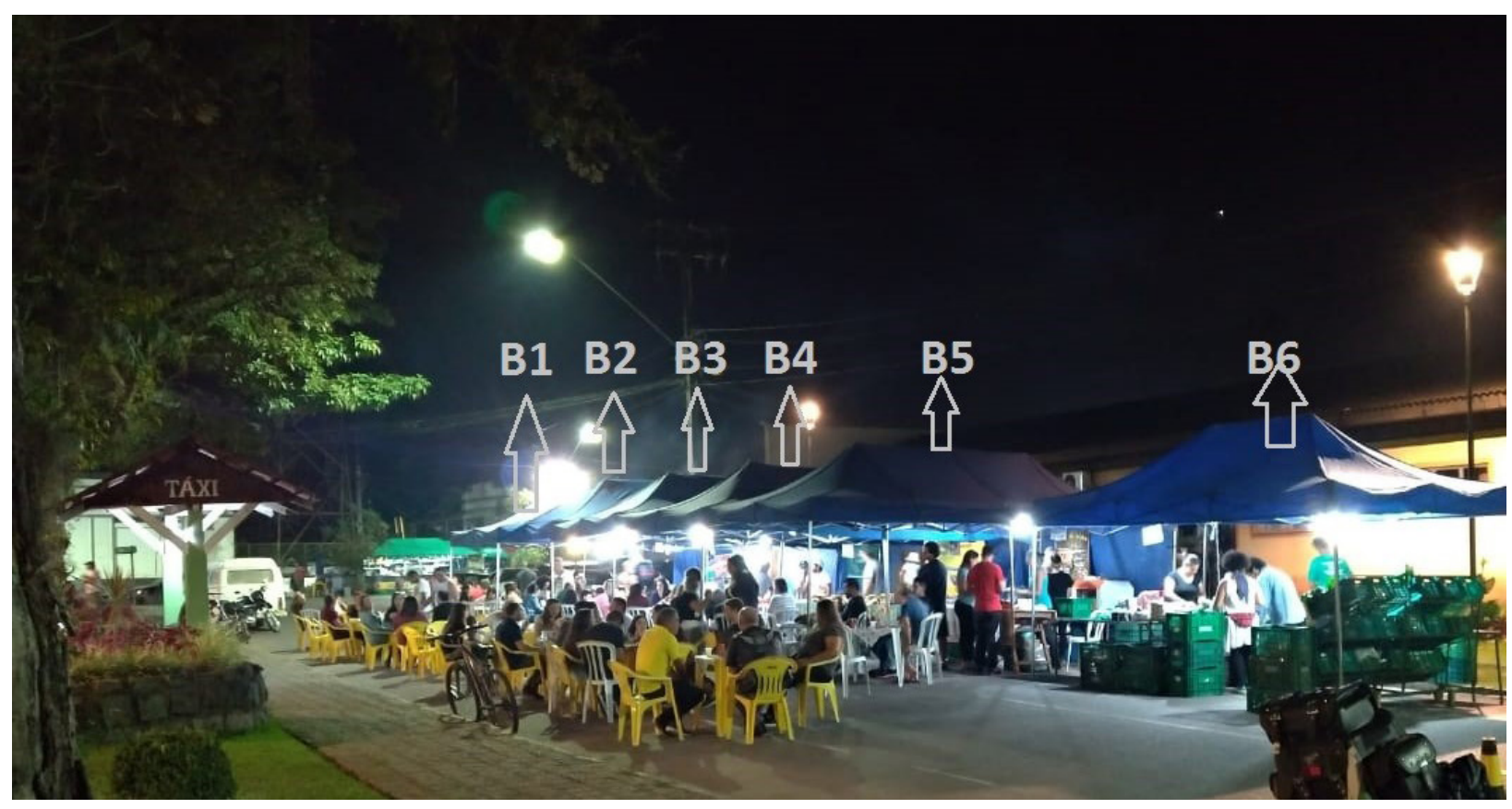

Fonte: Os autores (2019).

Na Feira também foi possível observar a presença de músicos de diferentes estilos musicais,

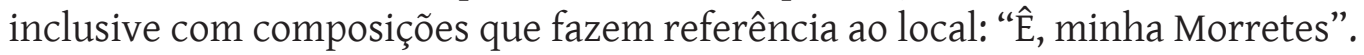

Os produtos eram comercializados em seis barracas (B) identificadas pelo sobrenome da família do produtor, que aqui passam ser denominadas simplesmente de barraca 1, 2, 3, 4, 5 e 6 . A barraca B1 comercializa espetinhos de carnes, assados e tapioca; a B2, salgados fritos, assados e doces; a B3, tempurá; a B4, mel e bebidas de fabricação caseira; a B5, pizza; e a B6, vegetais orgânicos.

Em cada barraca ficavam aproximadamente três feirantes com o predomínio de mulheres, principalmente na barraca 5, onde eram comercializas pizzas. Na barraca de mel e bebidas, ao contrário não havia mulheres (QUADRO 1). Quase todos feirantes eram identificados pelo uso da camiseta da Feira e pelo uso de avental. As mulheres ainda portavam touca, enquanto os homens bonés.

Quadro 1 - Número de atendentes por barraca e sexo na Feira do Produtor de Morretes

\begin{tabular}{|c|c|c|c|c|c|c|c|}
\hline GÊNERO & \multicolumn{6}{|c|}{ BARRACAS } & \multirow[t]{2}{*}{ TOTAL } \\
\hline & B1 & B2 & B3 & B4 & B5 & B6 & \\
\hline Mulher & 3 & 1 & 2 & 0 & 3 & 1 & 10 \\
\hline Homem & 1 & 1 & 1 & 2 & 0 & 1 & 6 \\
\hline TOTAL & 4 & 2 & 3 & 2 & 3 & 2 & 16 \\
\hline
\end{tabular}

Fonte: Os autores (2019). 
Relativo à organização inicial da Feira observou-se que as mulheres atuavam na colocação das mesas, toalhas, cadeiras e distribuição interna dos equipamentos nas barracas. Após, com a chegada dos "compradores", elas atuavam no preparo, na entrega até as mesas e balcão e também no caixa. Os homens atuavam na montagem e desmontagem das barracas, colocação das mesas e cadeiras, e, na entrega dos alimentos nas mesas e na retirada dos resíduos destas. Em momentos de menor público, os feirantes percorriam as outras barracas, permanecendo em diálogo.

A montagem da Feira iniciava com a montagem individual das barracas e com a montagem do espaço coletivo, por meio da distribuição de mesas e cadeiras. A montagem do coletivo era realizada por um dos feirantes, que se parasse para dialogar, outro feirante logo terminava. Após, um terceiro realizava a limpeza das mesas e das cadeiras. Na sequência, um quarto colocava as toalhas sobre as mesas, alinhando as cadeiras.

A Feira era frequentada por núcleos familiares que passavam nas barracas cumprimentando e permanecendo em diálogo com os feirantes. Durante a permanência dos compradores na Feira quase não se observa a utilização de aparelhos celulares.

No diálogo com diferentes feirantes constatou-se que eles sabiam as receitas dos alimentos produzidos pelo outro, mas não os faziam a fim de proporcionar uma cesta diferenciada de bens aos que buscavam a Feira. O Feirante B1 foi questionado para saber se dispunha de "biomassa de banana verde", mesmo observando que ele não expôs o produto sobre o balcão. Como resposta o Feirante B1 comentou saber da receita, porém disse que conhecia um produtor, indicando-o para que o procurasse. O mesmo questionamento foi feito aos Feirantes B3 e B5, os quais indicaram o mesmo produtor. Um dos feirantes disse que não tinha interesse em vender o produto, demonstrando-se flexível para compartilhar a receita, indicando o produtor para que fosse procurado para a compra. Destaca-se que, o produtor indicado pelos feirantes não tem barraca na Feira, mas todos tinham conhecimento que ele vendia o produto em sua residência.

\section{Resultados}

Com base na literatura elegeu-se a Feira do Produtor de Morretes para observação ou não de outras racionalidades que apontassem a outras economias, sendo a prova de resistências, ou ainda, alternativas contra hegemônicas à economia a de mercado. Também com base na literatura a pesquisa buscou observar no comportamento e no diálogo atitudes de reciprocidade, os quais demonstrariam vínculos sociais enraizados num espaço que supostamente seria de mercado.

Na Feira foi possível observar que os feirantes se organizam num espaço público. Os feirantes são: produtores, são vendedores, são trabalhadores da limpeza, são detentores de saberes de processos produtivos locais e de informações sobre o local e colaboram entre si para a existência da Feira.

Entre os produtos vendidos no local, poucos são produzidos fora do espaço Feira, o que faz da Feira um espaço de produção e venda direta ao comprador, resultando numa produção sem estoques, sem escalas ou incertezas, ou ainda, caracteriza-se por um modelo de produção que não promove a exaustão da natureza ou excedentes de resíduos. Portanto, em consonância com a natureza local.

Para além do modelo de produção, a Feira se mostra um local de alicerce para diferentes reciprocidades: simétricas - pela relação de interesse na troca estabelecida entre os compradores e vendedores diante da venda direta dos produtos; simétricas bilaterais - pela relação de amizade 
e confiança entre feirante e comprador; e simétricas ternárias - decorrente da mobilização dos feirantes de organizar seu espaço de compartilhamento de trabalho.

Na Feira, os feirantes cooperaram entre si para constituição de um espaço comum, ou seja, apesar das barracas identificadas pelo nome das famílias, eles se identificam como Feira, agindo num movimento de Homo situs, como sugerido por Zaoual (2003), criando assim um sítio simbólico de pertencimento, um lugar aonde eles são atores, agindo sobre dimensão social - por criarem um espaço de diálogo, cultural - pela manutenção do espaço, do alimento e da música, os quais transmitem hábitos, ambientais - por respeitarem os espaços físicos sem degradar, e políticas institucionais - por juntos tomarem decisões que transcendem a um simples espaço de produção e venda.

A Praça Rocha Pombo pode ser caracterizada como um sítio de pertencimento local, um bem comum, sobre o qual se estabelecem regras que se baseiam em princípios de reciprocidade, ou seja, em regras que vão muito além das regras do poder público (Estado) e/ou do poder econômico (Mercado).

Nas barracas, a divisão do trabalho parece ocorrer pela diferença da força física dos homens e das mulheres e pelos saberes tradicionais, sobre os quais as mulheres tradicionalmente atuavam, na culinária e nas atividades mais delicadas e os homens também, na construção e nos movimentos mais pesados. A divisão do trabalho não decorria da divisão social do trabalho, que caracteriza o modelo de produção capitalista e da economia de mercado, onde cada indivíduo exerce uma atividade, recebendo salário como o preço da mercadoria. Na Feira, observou-se reciprocidades simétricas ternárias, onde mesmo não tendo quem vendesse o produto, os vendedores lá presentes indicavam o seu produtor.

As relações entre feirantes e compradores também se estabelecem por diferentes reciprocidades, podendo ser assimétricas, mas fundamentalmente simétricas, as quais se estabeleciam pela dádiva da honra e do prestígio por intermédio de um contrato social firmado informalmente (MAUSS, 2003).

A Feira se mostra como um local de enraizamento social que se sobrepõe a um lugar de criação de lucro. Pode ser compreendia como um local de produção de identidade e cultura, fomentando um território construído como em Pecqueur (2009) que merece a leitura e sua referência nas investigações futuras. A Feira, como objeto de conhecimento científico sobre economias alternativas, está atravessada por racionalidades que confrontam o modelo hegemônico de produção industrial capitalista. Esta Feira apresenta-se como uma organização produtiva e social de resistência a globalização, pois nela se estabelece a produção e venda local, nela se desenvolvem princípios necessários à valorização humana e ecológica.

\section{Conclusão}

A possibilidade de se pensar outros modelos de desenvolvimento, especialmente pelas críticas de ser esse um mito (FURTADO, 1974) ou de ser Global que rompe com as especificidades do local (ZAOUAL, 2003), bem como de se pensar outras economias (POLANYI, 2012), a partir de relações sociais enraizadas, tal como as baseadas na reciprocidade (MAUSS, 2003) simétricas binárias ou ternárias (SABORIN, 2011), nos aponta um caminho para além da economia de mercado.

Provar que em meio a busca hegemônica da sociedade de mercado, onde os homens passaram a ser mercadorias e a natureza apenas fatores de produção, possam existir movimentos de resistência é no mínimo prazeroso para não dizer esperançoso. 
É com base nesses argumentos que a pesquisa intitulada com parte do título deste artigo teve início "Resistência e reciprocidade: comportamento in situ de pertencimento", objetivando averiguar a existência de uma economia contra hegemônica num espaço de troca monetária, para tal a observação etnográfica e de diálogos ocorreram na Feira do Produtor em Morretes, Litoral do Paraná.

Ocorrendo num espaço público, na Feira de Produtores de Morretes foi possível observar que os homens superaram suas racionalidades do Homo oeconomicus, para dar vasão as racionalidades situadas - Homo situs. Homens atores da sua própria história. Na Feira a economia é plural, o espaço de venda se abre para promoção cultural e fortalecimento das relações sociais, estabelecendo um sítio simbólico de pertencimento.

A racionalidade situada, que ora foi identificada pode ser fraca, pois ocorre num espaço público, o qual a qualquer momento pode ser regulamentado, reconstruído ou desfeito para que outra racionalidade passe a fazer parte daquele ambiente.

Tal como a racionalidade econômica, acredita-se que a homogeneidade de nenhuma racionalidade deve ser salutar para as sociedades, mesmo a baseada na reciprocidade, especialmente porque ela poderia ser assimétrica e estar relacionada a vingança, ainda pouco explorada na literatura.

Importa nestes resultados a constatação da existência de espaços de proximidade, onde ocorrem interações humanas, espaço de organização social, onde as normas não são delegadas a terceiros, aonde todos se responsabilizam pelo comum, responsabilizando-se pelo outro e pela natureza.

Além do papel social, a Feira provavelmente exerça um papel financeiro notório, não investigado, ficando assim recomendações para trabalhos futuros.

\section{Referências}

FURTADO, C. O mito do desenvolvimento econômico. São Paulo: Paz e Terra, 1974.

HAMMERSLEY, M. Reading Ethnographic Research: A Critical Guide. London: Routledge, 1990.

LESSA, S. Trabalho e proletariado no capitalismo contemporâneo. São Paulo: Cortez Editora, 2011.

MAUSS, M. Sociologia e antropologia. Título original: Sociologie et anthropologie. Tradução: Paulo Neves. São Paulo: Cosac Naify, 2003.

MORRETES (Município). Lei no 120 de 18 de novembro de 2010. INSTITUI A FEIRA LIVRE AGRÍCOLA DO MUNICÍPIO DE MORRETES - ESTADO DO PARANÁ E DÁ OUTRAS PROVIDÊNCIAS. 2010. Disponível em <http://www.morretes.pr.leg.br/camara/proposicao/lei-ordinaria/2010/1/0/349>. Acesso em: 16 jun. 2018.

PECQUEUR, B. A guinada territorial da economia global. Política e Sociedade, Florianópolis, v. 8, n. 14, p. 79-105, abr. 2009.

POLANYI, K. A subsistência do homem e ensaios correlatos. Rio de Janeiro: Contraponto, 2012.

SABOURIN, E. Teoria da reciprocidade e sócio-antropologica do desenvolvimento. Sociologias, Porto Alegre, v. 13, n. 27, p. 24-51, mai./ago. 2011.

SEN, A. Desenvolvimento como liberdade. São Paulo: Editora Companhia das Letras, 2010.

ZAOUAL, H. Globalização e diversidade cultural. Textos selecionados e traduzidos por Michel Thiollent. São Paulo: Cortez, 2003. 